\title{
Nanoparticles Using as Efficient Bioavailability in Drug Delivery System-Mini Review
}

\author{
Md. Shahed-Al-Mahmud* and Ezajul Hoque Bhuiuan \\ Department of Pharmacy, Stamford University Bangladesh, Bangladesh
}

Submission: December 12, 2017; Published: January 09, 2018

*Corresponding author: Md. Shahed-Al-Mahmud, Department of Pharmacy, Stamford University Bangladesh, 51, Siddeswari Road, Dhaka-1217, Bangladesh, Tel: +886 0966701647; E-mail: shahed.shuvo16@gmail.com

\section{Abstract}

Nanotechnology is manipulating matter at nanometer level and the application of the same to medicine is termed nanomedicine. It is a multidisciplinary field, which covers a vast and diverse array of the 21 st centuries. Nanomedicine, an offshoot of nanotechnology, refers to highly specific medical intervention at the molecular scale for curing disease or repairing damaged tissues, such as bone, muscle, or nerve. The burgeoning new field of nanomedicine opened up by rapid advances in health care, creates myriad new opportunities for advancing medical science in human health care. Applications of nanotechnology to medicine are leading to novel means of drug delivery system. Much nanotechnology research is focused on the bioavailability of poorly soluble drug in several diseases. The goal of this mini-review is to highlight the principles of nanoparticle design for drug delivery and applications to different organs. In addition to breakthroughs innovative forms of treatment, this review describes therapeutic uses of nanomedicine, such as bioavailability of drug delivery systems.

Keywords: Nanotechnology; Nanomedicine; Bioavailability; Drug delivery; Nanoparticles; Applications; Treatment

Abbreviations: NPs = Nanoparticles; BBB = Blood-Brain Barrier

\section{Introduction}

Nanotechnology is an emerging interdisciplinary revolution in different therapeutic areas over the last decade, including materials science, medicine, and drug delivery system [1]. The essence of this new technology has a great and significant impact in the field of medicine, diagnosis and drug delivery [2]. In the last two decades, number of Nanoparticle-based drug delivery system developed for the treatment of cancer [3], diabetes [4], pain [5], asthma [6], allergy [7], infections [8], and so on [9]. The significant benefits using nanoscale agent are more effective and convenient routes of administration [10], lower therapeutic toxicity [11], extend the drug bioavailability [12], as well as ultimately reduce health-care costs [13]. Nanoparticles (NPs) also use for optimizing drug formulations [14], increasing drug solubility [15] and altering the pharmacokinetics to sustain the release of the drug [16], thereby prolonging its bioavailability [17]. The diverse platforms of the NPs are nanomedicine which can utilize to develop more sophisticated, cell-targeted therapies [18] and to combine different drugs into a single nanotherapeutic agent for synergistic therapeutic benefits [19].

Nanomedicine is a rapidly growing area of medical research that focused on developing NPs for prophylactic [20], diagnostic [21], and therapeutic applications [13]. Nanomedicine promises an endless range of medical applications from efficient bioavailability to drug delivery and therapeutics [22]. The promising approach of nanomedicines provide us with many biological processes [23], cellular mechanisms [24], and organic molecules [25]. Currently, nanomedicine utilized in wide-ranging areas, and these applications have a potential to revolutionize the way we may target efficiently in drug delivery system in future. Different types of NPs have a relevant position in the global agenda for future development of medical research in the $21^{\text {st }}$ Century.

\section{Nanoparticles in Ocular Drug Delivery System}

The number of challenges associated with the treatment of ocular diseases. In general, the major problem in ocular therapeutics is to maintain an effective drug bioavailability at the site of action for an appropriate period of time, in order to achieve the expected pharmacological response [26]. NPs minimize side-effects and facilitate effective drug bioavailability. Nanosuspensions, solid lipid NPs, and liposomes have led to the solving of various solubility-related problems of poorly soluble as well less bioavailable drugs [27]. Nanospheres and liposomes, can provide protection for the drug encapsulated into them, and thus prolonged exposure to the drug by controlled release. To 
develop a promising and suitable ocular drug delivery system [28]. Liposomes attach to the hydrophobic corneal epithelium, where they continuously release the bound drug content, improving pharmacokinetics and decreasing toxic side effects [29]. Fluconazole-loaded liposome applied to the rabbit keratitis models, results showed that therapy with liposomal fluconazole was successful at eliminating infection and was superior to the control.

\section{Nanoparticles in Neural Drug Delivery}

The blood-brain barrier (BBB) represents an insurmountable barrier for the majority of drugs including anticancer agents, antibiotics, peptides and macromolecular drugs [30]. The polymer used for the majority of nanoparticles employed for the transport of drugs across the BBB [31]. This polymer is about the most rapidly biodegrading artificial polymers [32]. The first drugs that were transported across the BBB using nanoparticles were dalargin [33]. Dalargin is a hexapeptide Leu-enkephalin analogue with the sequence Tyr-d- Ala-Gly-Phe- Leu-Arg. Liposomes" are nanoscale vesicles having a phospholipid bilayer membrane and an aqueous core [34]. Liposomes have recently developed for the treatment of brain tumors but are still in the investigational stage in that setting [35]. In a number of studies, doxorubicin bound to nanoparticles has been shown to cross the intact BBB and reach therapeutic levels in the brain as well as to prolong survival times significantly in rats with glioblastomas [36].

\section{Nanoparticles in Cancer Drug Delivery}

NPs used for anticancer drug delivery can be made from a variety of materials, including polymers, dendrimers, liposomes, viruses, carbon nanotubes, and metal such as iron oxide and gold NPs [37]. The previous study reported that doxorubicin carried out using titanium dioxide (TiO2) NPs for anticancer efficacy enhancement on human hepatocarcinoma and side effect attenuation [38]. Liposome-based transmembrane carrier systems have the ability to target intracellular delivery of vincristine. Its clinical trial data demonstrated that it has longer blood circulation half-life, higher accumulation in tumors, and more sustained drug release profiles than free vincristine. Therefore, liposomal vincristine can potentially increase the efficacy of vincristine and decrease adverse side effects of the drug [13]. Liposomal formulations of daunorubicin also approved for the treatment of metastatic breast cancer and AIDSrelated Kaposi's sarcoma [39]. In vitro study, drugs methotrexate covalently linked to carbon nanotubes were shown to be more effectively internalized into cells compared with free drug alone [40].

\section{Nanoparticles in Diabetes Drug Delivery}

The NPs employed for oral insulin delivery include prodrugs (insulin-polymer conjugation), micelles, liposomes, solid lipid NPs of biodegradable polymers [41]. Nanoparticulated insulin delivery approaches mainly aim to develop drug preparations which can be orally administered and get absorbed in the intestine [42]. A large variety of new Nanoparticle is under development combining chitosan, for mucosa adhesion with other polymers such as hydroxypropyl methylcellulose phthalate for pH-sensitivity [43], alginate for improved loading capacity and activity maintenance [44], a gel formulation with the negatively charged sodium lauryl sulfate [45], or even chitosanreduced gold [46]. The study showed that nasal administration of insulin-loaded, chitosan-reduced gold nanoparticles (GNPs) improved Pharmacodynamics activity of insulin [47]. Recently published nanoparticle preparation for oral insulin delivery includes a multilayer approach with subsequent deposition of poloxamer, chitosan, and albumin on sub-micron particles consisting of insulin, alginate and dextran sulfate [48]. They claim a $40 \%$ decrease in glucose level over $24 \mathrm{~h}$ and three-times better bioavailability compared to free insulin orally administered [49]. Chitosan has been used to protect protein drugs from gastric enzymes [50] and facilitate the absorption of hydrophilic macromolecules [51]. Furthermore, chitosan nanoparticles have been found to enhance the intestinal absorption of protein molecules to a greater extent than aqueous solutions of chitosan in vivo.

\section{Discussion}

Controlled drug delivery systems have several advantages compared to the traditional forms of drugs. A drug is transported to the place of action, hence, its influence on vital tissues and undesirable side effects can be minimized. Accumulation of therapeutic compounds in the target site increases and, consequently, the required doses of drugs are lower. This modern form of therapy is especially important when there is a discrepancy between the dose or the bioavailability of a drug and its therapeutic results [52]. Despite numerous scientific efforts, efficient ocular drug delivery remains a challenge for pharmaceutical scientists. Most ocular diseases are treated by topical drug application in the form of solutions, suspensions, and ointment [53]. These conventional dosage forms suffer from the problems of poor ocular bioavailability, because of various anatomical and patho physiological barriers prevailing in the eye [54]. NPs formulated drug provides significant bioavailability to ocular drug delivery system. Recent findings and applications of various nanoparticulate systems like microemulsions, nanosuspensions, nanoparticles, liposomes, niosomes, dendrimers and cyclodextrins in the field of ocular drug delivery and also depicts how the various upcoming of nanotechnology like nanodiagnostics, nanoimaging and nanomedicine can be utilized to explore the frontiers of ocular drug delivery and therapy. NPs utilized as drug delivery agents which use for delivering drugs to the brain across the blood-brain barrier (BBB) may provide a significant advantage to current strategies [55]. The primary advantage of NP carrier technology is that NPs mask the blood-brain barrier limiting characteristics of the therapeutic drug molecule. Furthermore, this system may slow drug release in the brain, decreasing peripheral toxicity, 
increased bioavailability. NP technology appears to have significant promise in delivering therapeutic molecules across the BBB. NPs are rapidly progressing and implemented to solve several limitations of conventional drug delivery systems such as nonspecific bio distribution and targeting, lack of water solubility, poor oral bioavailability, and low therapeutic indices. To improve the bio distribution of cancer drugs, nanoparticles have been designed for optimal size and surface characteristics to increase their circulation time in the bloodstream [56]. Multifunctional and multiplex nanoparticles are now being actively investigated and are on the horizon as the next generation of nanoparticles, facilitating personalized and tailored cancer treatment. There are many ongoing investigations to improve the oral bioavailability of peptide and protein formulations. Bioadhesive polysaccharide chitosan NPs would seem to further enhance intestinal absorption of them [57].

\section{Conclusion}

New science and technologies are previously making their way into all aspects of dental practice and have changed traditional approaches to diagnostics, risk assessment, prevention, and many other procedures. Nanotechnology promising in the drug delivery system. Nanotechnology-namely safety, cost, and ethical considerations. Nanotechnology revolutionizes our approach to current therapeutic challenges like drug delivery, bioavailability and will enable us to address currently unsolvable problems. We expect that Nanotechnology with novel engineering approaches that result in optimally designed nanoparticles, we will see an increasing number of multifunctional nanoparticles in the future for drug delivery system.

\section{References}

1. Vasir JK, Labhasetwar V (2005) Targeted drug delivery in cancer therapy. Technology in cancer research \& treatment, 4(4): 363-374.

2. Mohamed A, Xing MM (2012) Nanomaterials and nanotechnology for skin tissue engineering. Int J Burns Trauma 2(1): 29-41.

3. Brannon-Peppas L, Blanchette JO (2004) Nanoparticle and targeted systems for cancer therapy. Adv Drug Deliv Rev 56(11): 1649-1659.

4. Chalasani KB, Russell-Jones GJ, Jain AK, Diwan PV, Jain SK, et al.(2007) Effective oral delivery of insulin in animal models using vitamin $B_{12}$ coated dextran nanoparticles. J Control Release 122(2): 141-150.

5. Hua S, Cabot PJ (2013) Targeted nanoparticles that mimic immune cells in pain control inducing analgesic and anti-inflammatory actions: a potential novel treatment of acute andchronic pain conditions. Pain Physician 16(3): E199-E216.

6. Kleinstreuer C, Zhang Z, Donohue J (2008) Targeted drug-aerosol delivery in the human respiratory system. Annu Rev Biomed Eng 10: 195-220.

7. Calvo P, Gouritin B, Villarroya H, Eclancher F, Giannavola C, et al. (2002) Quantification and localization of PEGylated polycyanoacrylate nanoparticles in brain and spinal cord during experimental allergic encephalomyelitis in the rat. Eur J Neurosci 15(8): 1317-1326.

8. Zhang W, Yang H, Kong X, Mohapatra S, Juan-Vergara SH, et al. (2005) Inhibition of respiratory syncytial virus infection with intranasal siRNA nanoparticles targeting the viral NS1 gene. Nat Med 11(1): 56-62.
9. Kawasaki ES, Player A (2005) Nanotechnology, nanomedicine, and the development of new, effective therapies for cancer. Nanomedicine 1(2): 101-109.

10. Cheng Y, Xu Z, Ma M, Xu T (2008) Dendrimers as drug carriers: applications in different routes of drug administration. J Pharm Sci 97(1): 123-143.

11. Zhang XD, Wu HY, Wu D, Wang YY, Chang JH, et al. (2010) Toxicologic effects of gold nanoparticles in vivo by different administration routes. Int J Nanomedicine 5: 771-781.

12. Merisko-Liversidge EM, Liversidge GG (2008) Drug nanoparticles: formulating poorly water-soluble compounds. Toxicol Pathol 36(1): 43-48.

13. Zhang L, Gu F, Chan J, Wang A, Langer R, et al. (2008) Nanoparticles in medicine: therapeutic applications and developments. Clin Pharmacol Ther 83(5): 761-769.

14. Mukherjee S, Ray S, Thakur R (2009) Solid lipid nanoparticles: a modern formulation approach in drug delivery system. Indian J Pharm Sci 71(4): 349-358.

15. Allen TM, Cullis PR (2004) Drug delivery systems: entering the mainstream. Science 303(5665): 1818-1822.

16. Kim DH, Martin DC (2006) Sustained release of dexamethasone from hydrophilic matrices using PLGA nanoparticles for neural drug delivery. Biomaterials 27(15): 3031-3037.

17. Sun J, Bi C, Chan HM, Sun S, Zhang Q, et al. (2013) Curcumin-loaded solid lipid nanoparticles have prolonged in vitro antitumour activity, cellular uptake and improved in vivo bioavailability. Colloids Surf B Biointerfaces 111: 367-375.

18. Wang C, Cheng L, Liu Z (2011) Drug delivery with up conversion nanoparticles for multi-functional targeted cancer cell imaging and therapy. Biomaterials 32(4): 1110-1120.

19. Liu Y, Guo Y, An S, Kuang Y, HeX, et al. (2013) Targeting caspase-3 as dual therapeutic benefits by RNAi facilitating brain-targeted nanoparticles in a rat model of Parkinson's disease. PloS one 8(5): e62905.

20. Date AA, Shibata A, Goede M, Sanford B, Bruzzo LK, et al. (2012) Development and evaluation of a thermo sensitive vaginal gel containing raltegravir efavirenz loaded nanoparticles for HIV prophylaxis. Antiviral Res 96(3): 430-436.

21. Weinstein JS, Varallyay CG, Dosa E, Gahramanov S, Hamilton B, et al. (2010) Super paramagnetic iron oxide nanoparticles: diagnostic magnetic resonance imaging and potential therapeutic applications in neurooncology and central nervous system inflammatory pathologies, a review. J Cereb Blood Flow Metab 30(1): 15-35.

22. Bawarski WE, Chidlowsky E, Bharali DJ, Mousa SA (2008) Emerging nano pharmaceuticals. Nanomedicine: Nanotechnology, Biology and Medicine 4(4): 273-282.

23. Song JY, Kim BS (2009) Rapid biological synthesis of silver nanoparticles using plant leaf extracts. Bioprocess Biosyst Eng 32(1):79-84.

24. Jiang W, Kim BY, Rutka JT, Chan WC (2008) Nanoparticle-mediated cellular response is size-dependent. Nature nanotechnology 3(3): 145150.

25. An BK, Kwon SK, Jung SD, Park SY (2002) Enhanced emission and its switching in fluorescent organic nanoparticles. J Am Chem Soc 124(48):14410-14415.

26. Fuente MDL, Raviña M, Paolicelli P, Sanchez A, Seijo B, et al. (2010) Chitosan-based nanostructures: a delivery platform for ocular therapeutics. Adv Drug Deliv Rev 62(1): 100-117.

27. Merisko-Liversidge E, Liversidge GG, Cooper ER (2003) Nanosizing: a formulation approach for poorly-water-soluble compounds. Eur $]$ Pharm Sci 18(2):113-120. 
28. Parveen S, Misra R, Sahoo SK (2012) Nanoparticles: a boon to drug delivery, therapeutics, diagnostics and imaging. Nanomedicine: Nanotechnology, Biology and Medicine 8(2):147-166.

29. Habib FS, Fouad EA, Abdel-Rhaman MS, Fathalla D (2010) Liposomes as an ocular delivery system of fluconazole: in-vitro studies. Acta Ophthalmol 88(8): 901-904.

30. Begley DJ (1996) The blood-brain barrier: principles for targeting peptides and drugs to the central nervous system. J Pharm Pharmacol 48(2): 136-146

31. Wohlfart S, Gelperina S, Kreuter J (2012) Transport of drugs across the blood-brain barrier by nanoparticles. J Control Release 161(2): 264273 .

32. Middleton JC, Tipton AJ (2000) Synthetic biodegradable polymers as orthopedic devices. Biomaterials 21(23): 2335-2346.

33. Alyautdin R, Gothier D, Petrov V, Kharkevich D, Kreuter J, et al. (1995) Analgesic activity of the hexapeptide dalargin adsorbed on the surface of polysorbate 80-coated poly (butylcyanoacrylate) nanoparticles. European journal of pharmaceutics and bio pharmaceutics 41(1): 4448.

34. Ruíz MA, Clares B, Morales ME, Gallardo V (2008) Vesicular lipidic systems, liposomes, PLO, and liposomes-PLO: characterization by electronic transmission microscopy. Drug Dev Ind Pharm 34(12) 1269-1276.

35. Paolo DD, Pastorino F, Brignole C, Marimpietri D, Loi M, et al. (2008) Drug delivery systems: application of liposomal anti-tumor agents to neuroectodermal cancer treatment. Tumori 94(2): 246-253.

36. Steiniger SC, Kreuter J, Khalansky AS, Skidan IN, Bobruskin AI, et al (2004) Chemotherapy of glioblastoma in rats using doxorubicinloadednanoparticles. Int J Cancer 109(5):759-767.

37. Anajwala CC, Jani GK, Swamy SV (2010) Current trends of nanotechnology for cancer therapy. Int J Pharm Sci Nanotechnol 3: 1043-1056.

38. Chen Y, Wan Y, Wang Y, Zhang H, Jiao Z (2011) Anticancer efficacy enhancement and attenuation of side effects of doxorubicin with titanium dioxide nanoparticles. Int J Nanomedicine 6: 2321-2326.

39. Cho K, Wang X, Nie S, Chen ZG, Shin DM, et al. (2008) Therapeutic nanoparticles for drug delivery in cancer. Clin Cancer Res 14(5):13101316.

40. Wu W, Wieckowski S, Pastorin G, Benincasa M, Klumpp C, et al. (2005) Targeted delivery of amphotericin B to cells by using functionalized carbon nanotubes. Angew Chem Int Ed Engl 44(39): 6358-6362.

41. Arbit E, Kidron M (2009) Oral insulin: the rationale for this approach and current developments. J Diabetes Sci Technol 3(3): 562-567.

42. Tran HNA, Sousa F, Moda F, Mandal S, Chanana M, et al. (2010) A novel class of potential prion drugs: preliminary in vitro and in vivo data for

This work is licensed under Creative

Commons Attribution 4.0 Licens

DOI: 10.19080/MABB.2018.03.555602 multilayer coated gold nanoparticles. Nanoscale 2(12): 2724-2732.

43. Makhlof A, Tozuka Y, Takeuchi H (2011) Design and evaluation of novel $\mathrm{pH}$-sensitive chitosan nanoparticles for oral insulin delivery. Eur J Pharm Sci 42(5): 445-451.

44. Zhang Y, Wei W, Lv P, Wang L, Ma G, et al. (2011) Preparation and evaluation of alginate-chitosan microspheres for oral delivery of insulin. Eur J Pharm Biopharm 77(1):11-19.

45. Elsayed A, Al-Remawi M, Qinna N, Farouk A, Al-Sou'od KA, et al. (2011) Chitosan-sodium lauryl sulfate nanoparticles as a carrier system for the in vivo delivery of oral insulin. AAPS PharmSciTech 12(3): 958-964.

46. Bhumkar DR, Joshi HM, Sastry M, Pokharkar VB (2007) Chitosan reduced gold nanoparticles as novel carriers for transmucosal delivery of insulin. Pharm Res 24(8): 1415-1426.

47. Chalasani KB, Russell-Jones G, Yandrapu SK, Diwan PV, Jain SK, et al. (2007) A novel vitamin $B_{12}$ - nanosphere conjugate carrier system for peroral delivery of insulin. J Control Release 117(3): 421-429.

48. Woitiski CB, Neufeld RJ, Veiga F, Carvalho RA, Figueiredo IV, et al. (2010) Pharmacological effect of orally delivered insulin facilitated by multilayered stable nanoparticles. Eur J Pharm Sci 41(3-4): 556-563.

49. Damgé C, Socha M, Ubrich N, Maincent P (2010) Poly ( $\varepsilon$-caprolactone)/ eudragit nanoparticles for oral delivery of aspart-insulin in the treatment of diabetes. J Pharm Sci 99(2): 879-889.

50. Ramadas M, Paul W, Dileep K, Anitha MRY, Sharma C, et al. (2000) Lipoinsulin encapsulated alginate-chitosan capsules: intestinal delivery in diabetic rats. J Microencapsul 17(4): 405-411.

51. Ward PD, Tippin TK, Thakker DR (2000) Enhancing paracellular permeability by modulating epithelial tight junctions. Pharm Sci Technolo Today 3(10): 346-358.

52. Wilczewska AZ, Niemirowicz K, Markiewicz KH, Car H (2012) Nanoparticles as drug delivery systems. Pharmacol Rep 64(5): 10201037.

53. Lee VH, Robinson JR (1986) Topical ocular drug delivery: recent developments and future challenges. J Ocul Pharmacol 2(1): 67-108.

54. Granero GE, Longhi MR (2010) Promising complexes of acetazolamide for topical ocular administration. Expert Opin Drug Deliv 7(8): 943953.

55. Lockman P, Mumper R, Khan M, Allen D (2002) Nanoparticle technology for drug delivery across the blood-brain barrier. Drug Dev Ind Pharm 28(1): 1-13.

56. Danhier F, Feron O, Préat V (2010) To exploit the tumor microenvironment: passive and active tumor targeting of nanocarriers for anti-cancer drug delivery. J Control Release 148(2): 135-146.

57. Sarmento B, Ribeiro A, Veiga F, Sampaio P, Neufeld R, et al. (2007) Alginate/chitosan nanoparticles are effective for oral insulin delivery. Pharm Res 24(12): 2198-2206.

\author{
Your next submission with Juniper Publishers \\ will reach you the below assets \\ - Quality Editorial service \\ - Swift Peer Review \\ - Reprints availability \\ - E-prints Service \\ - Manuscript Podcast for convenient understanding \\ - Global attainment for your research \\ - Manuscript accessibility in different formats \\ ( Pdf, E-pub, Full Text, Audio) \\ - Unceasing customer service
}

Track the below URL for one-step submission https://juniperpublishers.com/online-submission.php 